\section{Antioxidant Activity of Fruits Produced in Northern Greece}

\author{
Antonios Petridis ${ }^{1}$ \\ Department of Horticulture, Laboratory of Pomology, Aristotle University of \\ Thessaloniki, 54124 Thessaloniki, Greece
}

Magdalene Koukourikou

Department of Horticulture, Laboratory of Biology of Horticulture, Aristotle University of Thessaloniki, 54124 Thessaloniki, Greece

Thomas Sotiropoulos

Pomology Institute (N.AG.RE.F.), P.O. Box 122, 59200 Naoussa, Greece

Dimitrios Stylianidis

Egnatia 5, 59100 Veria, Greece

Additional index words. ascorbic acid, FRAP, cornelian cherry

\begin{abstract}
The antioxidant activities ( $\mu \mathrm{mol}$ ascorbic acid equivalent/g fresh weight) of the edible part of fruits grown in northern Greece were determined using the ferric-reducing antioxidant power (FRAP) assay. Differences were observed among species as well as cultivars of the same species. Cornelian cherry had the highest FRAP value followed by jujube. Cherries, black grapes, and blackberry showed high activity followed by pears, persimmons, plums, peaches, white grapes, pomegranates, apples, nectarines, kiwifruits, quinces, figs, and apricots.
\end{abstract}

Various studies have demonstrated a close link between oxidative stress and development of different ailments such as cancer and cardiovascular and neurodegenerative diseases (Halvorsen et al., 2002). The human body has an antioxidant defense system and it has been proved that a diet rich in antioxidants strengthens this system. It has been postulated that a network of antioxidants with different chemical properties may work in a synergistic way protecting the cells from damage. On the other hand, plants produce a wide range of compounds with strong antioxidant activity such as vitamins $\mathrm{C}$ and $\mathrm{E}$, flavonoids, and other phenolic compounds to protect themselves from pests and diseases (De Gara et al., 2003; Garcia-Alonso et al., 2004; Halvorsen et al., 2002; Hodges et al., 2004; Strangeland et al., 2009). Plant-derived antioxidants have been shown to function as singlet and triplet oxygen quenchers, enzyme inhibitors, and synergists (Larson, 1988). The important role of plant antioxidants in human health has prompted research in this field (Pellegrini et al., 2003; Strangeland et al., 2009; Wang and Cao, 1996). Furthermore, during the past decades, several analytical methods have been developed for measuring antioxidant activity of plant tissues (Benzie and Strain, 1996; Ghiselli et al., 1995; Pellegrini et al., 2000; Wang et al., 1997).

Antioxidant activity of plants is influenced by several factors such as the geographic location, the growth practices, and particularly

Received for publication 26 Apr. 2010. Accepted for publication 6 July 2010 .

${ }^{1}$ To whom reprint requests should be addressed; e-mail antonispet@hotmail.com. the genetic factors (Wang and Cao, 1996). Not only different species, but also different cultivars of the same species present variations in their antioxidant profile. For example, a recent study has shown that the apple cultivar may substantially influence the fruit phenolic content and total antioxidant activity (Wojdyło et al., 2008)

Because fruits of northern Greece are exported to the rest of Europe and taking into consideration that the previously mentioned factors influence antioxidant activity, it was considered reasonable to analyze the edible part of several fruits grown in this area to evaluate them according to their antioxidant activity. Moreover, some cultivars used in the present work have not been tested.

\section{Materials and Methods}

The fruit samples were collected from orchards in northern Greece. The species and the number of cultivars examined are shown in Table 1. Fruits were collected at the maturity stage for harvest. After harvest, the fruits were immediately transported to the laboratory in ice coolers, washed, peeled-if necessary, to get only the edible part (Table 1), and analyzed. The fractions were prepared immediately to prevent degradation of the fruits.

For the determination of total antioxidant activity, a weighed amount ( $1 \mathrm{~g}$ ) of the edible part (pulp plus peel for most fruits, pulp for some of them, and arils for pomegranates; see also Table 1) of each sample was extracted twice with $10 \mathrm{~mL}$ of a solution consisting of $50 \%$ methanol in $1.2 \mathrm{M} \mathrm{HCl}(1: 10 \mathrm{w} / \mathrm{v})$ at $4{ }^{\circ} \mathrm{C}$ for 24-h intervals. Five to 10 fruits per sample were used for large and small fruits, respectively. Fruits per sample were pooled from five trees. Three replications of five trees were used (three $\times$ five $=15$ trees in total). Sample extracts were analyzed for their antioxidant activity by ferric-reducing antioxidant power (FRAP) assay (Benzie and Strain, 1996) using a Camspec M106 (UK) spectrophotometer (Camspec Analytical Instruments Ltd., Leeds, UK) at $593 \mathrm{~nm}$. The FRAP values of the samples were expressed as $\mu \mathrm{mol} \mathrm{L-ascorbic} \mathrm{acid}$ equivalents (AAE) per gram fresh weight (FW) by using an equation in which the FRAP values of standard L-ascorbic acid solution were used.

Statistical analysis was performed using SPSS statistical package (Version 15.0; SPSS Inc., Chicago, IL). Differences among cultivars were evaluated by using the least significant difference test at $P \leq 0.05$.

\section{Results and Discussion}

The antioxidant activities of the fruits tested, expressed as FRAP values of the average of the cultivars of each species, are shown in Table 1. Fruits of different species exhibited a varying degree of antioxidant activity ranging from 4.0 to $80.15 \mu \mathrm{mol} \mathrm{AAE} / \mathrm{g}$ FW. Cornelian cherries possessed the first place followed by jujube. Fruit with high antioxidant activities were cherries, black grapes, and blackberries. In descending antioxidant activity, the order was: cornelian cherry $>$ jujube $>$ cherry $>$ red grape $>$ blackberry $>$ pear $>$ persimmon $>$ plum $>$ white grape $>$ peach $>$ pomegranate $>$ apple $>$ nectarine $>$ kiwifruit $>$ quince $>$ fig $>$ apricot. The order presents similarities as well as differences with the order given by GarciaAlonso et al. (2004) who used the thiobarbituric acid-reactive substances method and Halvorsen et al. (2002) who used a modified FRAP method. However, their studies did not include some species and/or cultivars presented here. Generally, differences were also detected in the results of other researchers and may be attributed to the different analytical methods adopted and other factors such as the cultivars used, geographical origin, cultural practices, maturity at harvest, and storage conditions (Guo et al., 2003; Van der Sluis et al., 2001). Although fruit ranking based on antioxidant activity was in partial disagreement between different studies, it is known that berries are very effective because of their high content of phenolic acids and flavonoids such as anthocyanins, which have demonstrated strong antioxidant activity in a different model system (Halvorsen et al., 2002; Pellegrini et al., 2003).

Differences in antioxidant activity were observed among cultivars of the same species as shown in Figures 1 through 8. Apples showed a wide range in antioxidant activity values (3.6 to $29.5 \mu \mathrm{mol}$ AAE/g FW; Fig. 1) and these results are in agreement with the findings of Wojdyło et al. (2008). Generally, apple cultivars with dark red skin had higher antioxidant activity than other ones (Karadeniz et al., 2005). The previous researchers proposed that the higher antioxidant activity is mostly attributed to anthocyanins located in the skins of apples. In our work, where 
apples that were analyzed were unpeeled, green ('Mutsu', 'Granny Smith') and yellow ('Golden Smoothee') had lower antioxidant activity than the red ones ('Starking Delicious', 'Gala Shniga', 'Galaxy', 'Red Chief'). However, differences were also found among red apple cultivars with some of them having values similar as those of green ones. Wojdyło et al. (2008) studying the polyphenolic compounds of 67 apple varieties found that anthocyanins are minor phenolic components of apple. Grape cultivars showed also an extended variation in antioxidant activity (Fig. 2) with red ones ('Cabernet Sauvignon', 'Xinomavro Naoussas', 'Cardinal', 'Muscat Hamburg') being superior, in agreement with other reports (Pellegrini et al., 2003). However, 'Cardinal', a red cultivar, had a lower value than 'White Muscat'. The antioxidant activities of peach cultivars ranged from 7.0 to $20.5 \mu \mathrm{mol} \mathrm{AAE} / \mathrm{g}$ FW (Fig. 3). The highest value was measured in 'Rubidoux', a green-yellow cultivar, whereas one of the lowest values was measured in 'Royal Glory', a red cultivar. Among the cherry cultivars, Sweet Heart and Tragana Edessis had high values (Fig. 4) and ranked third below cornelian cherries and jujube. Among plum cultivars, Black Amber, a darkcolored cultivar, had the highest value (Fig. 5), showing that in this case, anthocyanins may be responsible for the high antioxidant activity, as was shown by other researchers too (Pellegrini et al., 2003; Vangdal and Slimestad, 2006). Among the pear cultivars tested, Kalliopi had the lowest $(11.0 \mu \mathrm{mol} \mathrm{AAE} / \mathrm{g}$ FW) and 'Verdi' the highest antioxidant activity (29.6 $\mu \mathrm{mol} \mathrm{AAE/g} \mathrm{FW)} \mathrm{(Fig.} \mathrm{6).}$ Concerning the cornelian cherries, differences existed between cultivars with large fruits and cultivars with small fruits (Fig. 7). It is probable that the greater contribution of skin (exocarp) than fleshy tissue (mesocarp) of small fruits is responsible for this, because it was shown that exocarp had higher antioxidant activity than mesocarp, because of the presence of anthocyanins (Hakkinen et al., 1999). Small cornelian cherries were analyzed whole, whereas large ones were sampled as half fruits. A wide range of FRAP values among other cornelian cherry cultivars was observed by Tural and Koca (2008) who attributed the high antioxidant activities to high ascorbic acid, anthocyanins, and total phenols contents. In persimmon, 'Rojo brillante', a brown-colored cultivar, and 'Jiro', an orange one, had similar antioxidant activities (18.10 and $17.0 \mu \mathrm{mol} \mathrm{AAE} / \mathrm{g} \mathrm{FW}$, respectively), whereas 'Hana Fuyu' (orange) had lower $(11.40 \mu \mathrm{mol} \mathrm{AAE} / \mathrm{g} \mathrm{FW})$. Among kiwifruits, 'Tsechelidis' had higher antioxidant activity value $(11.1 \mu \mathrm{mol} \mathrm{AAE} / \mathrm{g} \mathrm{FW})$ than 'Hayward' (8.7 $\mu \mathrm{mol}$ AAE/g FW), and 'Bebeko' apricot higher (4.8 $\mu \mathrm{mol}$ AAE/g FW) than 'Tirinthos' apricot (3.2 $\mu$ mol AAE/ g FW). The pomegranate genotype 'Almaliotis' showed higher antioxidant activity than the rest genotypes and the cultivar Wonderful (Fig. 8). In the present research, the fruits tested had variable coloration in peel as well as in pulp: white, yellow, green, orange, red, and dark red.

Table 1 . Total antioxidant activity (mean values $\pm \mathrm{SE}$ of three replications) of fruits.

\begin{tabular}{|c|c|c|c|c|}
\hline Fruit cultivar & Botanical name & Family & $\begin{array}{l}\text { Antioxidant activity } \\
(\mu \mathrm{mol} \text { AAE/g FW })\end{array}$ & Range \\
\hline$\overline{\text { Cornelian cherry }(4)^{z}}$ & Cornus mas & Cornaceae & $80.15 \pm 19.78$ & $54.8-100.8$ \\
\hline Jujube-Gigas $(1)^{\mathrm{y}}$ & Zizyphus jujube & Ramnaceae & $69.55 \pm 0.35$ & - \\
\hline Sweet cherry (4) & Prunus avium & Rosaceae & $32.60 \pm 10.30$ & $17.5-41.0$ \\
\hline Black grape (4) & Vitis vinifera & Ramnaceae & $31.40 \pm 13.19$ & $11.7-43.1$ \\
\hline Blackberry (1) & Rubus spp. & Rosaceae & $26.10 \pm 0.52$ & - \\
\hline Pear (6) & Pyrus communis & Rosaceae & $20.57 \pm 5.18$ & $11.0-29.6$ \\
\hline Persimmon $(3)^{y}$ & Diospyros kaki & Ebenaceae & $15.51 \pm 3.23$ & $11.4-18.1$ \\
\hline Plum (3) & Prunus domestica & Rosaceae & $15.13 \pm 4.44$ & $10.5-20.5$ \\
\hline Peach (10) & Prunus persica & Rosaceae & $14.16 \pm 4.12$ & $7.0-20.5$ \\
\hline White grape (2) & Vitis vinifera & Ramnaceae & $14.00 \pm 4.90$ & $9.1-18.9$ \\
\hline Pomengranate $(5)^{y}$ & Punica granatum & Punicaceae & $12.56 \pm 2.52$ & $10.0-15.5$ \\
\hline Apple (10) & Malus $\times$ domestica & Rosaceae & $10.99 \pm 8.60$ & $3.6-29.5$ \\
\hline Nectarine-Caltezi (1) & Prunus persica & Rosaceae & $10.40 \pm 0.56$ & - \\
\hline Kiwifruit $(2)^{y}$ & Actinidia deliciosa & Actinidiaceae & $9.90 \pm 1.20$ & $8.7-11.1$ \\
\hline Quince (3) & Cydonia oblonga & Rosaceae & $8.93 \pm 1.10$ & $7.6-10.0$ \\
\hline Fig-Veroia $^{\mathrm{y}}(1)$ & Ficus carica & Moraceae & $7.05 \pm 0.77$ & - \\
\hline Apricot (2) & Prunus armeniaca & Rosaceae & $4.00 \pm 0.80$ & $3.2-4.8$ \\
\hline
\end{tabular}

${ }^{2}$ Number of cultivars tested.

'Peeled.

$\mathrm{AAE}=$ ascorbic acid equivalent; $\mathrm{FW}=$ fresh weight.

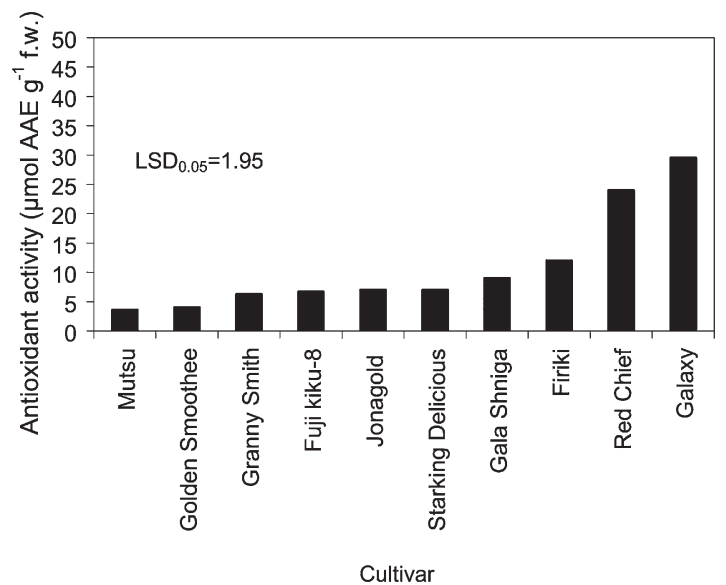

Fig. 1. Antioxidant activity of apple cultivars. Harvest dates from left to right: 5 Sept., 15 Sept., 22 Oct., 8 Oct., 5 Sept., 6 Sept., 16 Aug., 25 Sept., 17 Sept., and 16 Aug.

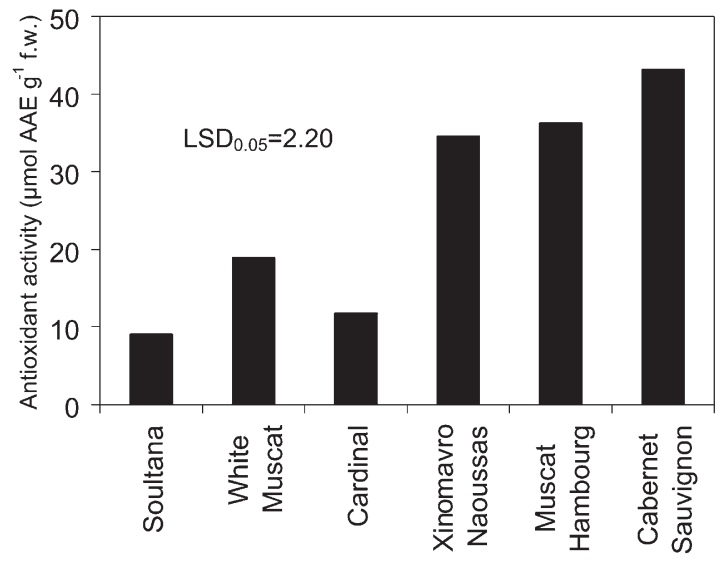

Cultivar

Fig. 2. Antioxidant activity of grape cultivars. Harvest dates from left to right: 28 Aug., 9 Sept., 8 Aug., 23 Sept., 1 Sept., and 18 Sept.

Generally, red-colored fruits had higher antioxidant activity than the others as a result of the high content of anthocyanins. However, investigators observed exceptions, as also happened in the present work. For example, the white-yellow-colored peach 'Maria Bianca' had higher activity (17.0 $\mu$ mol AAE/g FW) than the red 'Royal Glory' $(8.3 \mu \mathrm{mol}$ AAE/g FW). Anthocyanins may show high AAE, especially when measured with the FRAP 


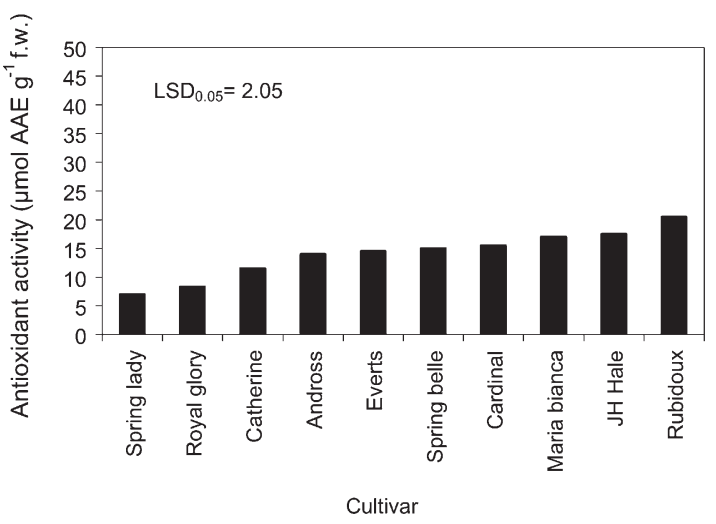

Fig. 3. Antioxidant activity of peach cultivars. Harvest dates from left to right: 15 June, 7 July, 17 July, 12 Aug., 27 Aug., 25 June, 27 June, 20 July, 9 Aug., and 2 Sept.



Fig. 4. Antioxidant activity of cherry cultivars. Harvest dates from left to right: 2 June, 5 June, 14 June, and 10 June.

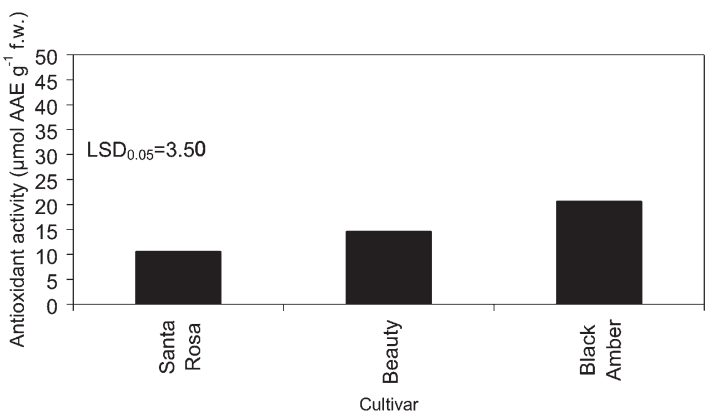

Fig. 5. Antioxidant activity of plum cultivars. Harvest dates from left to right: 22 July, 15 June, and 16 July.

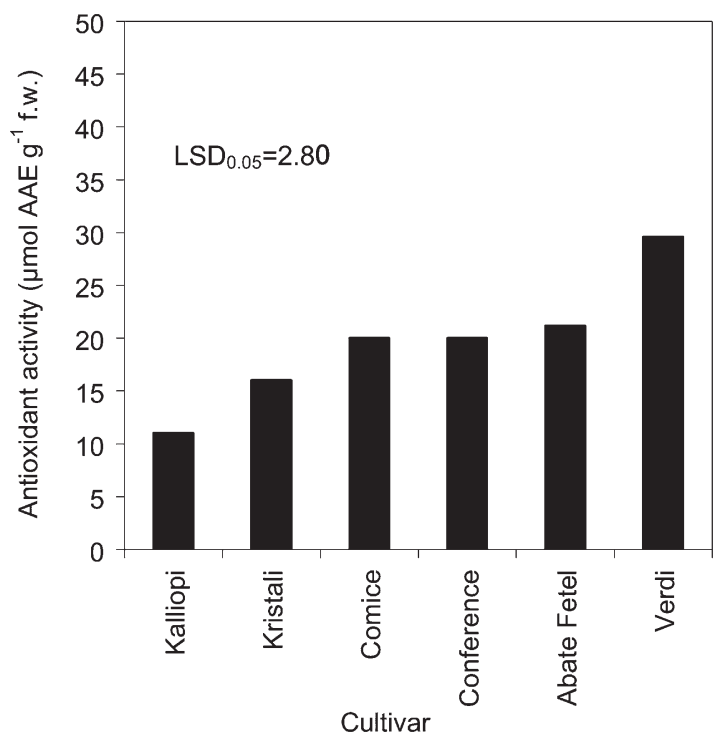

Fig. 6. Antioxidant activity of pear cultivars. Harvest dates from left to right: 17 July, 10 Aug., 13 Sept., 4 Sept., 9 Sept., and 8 Aug.

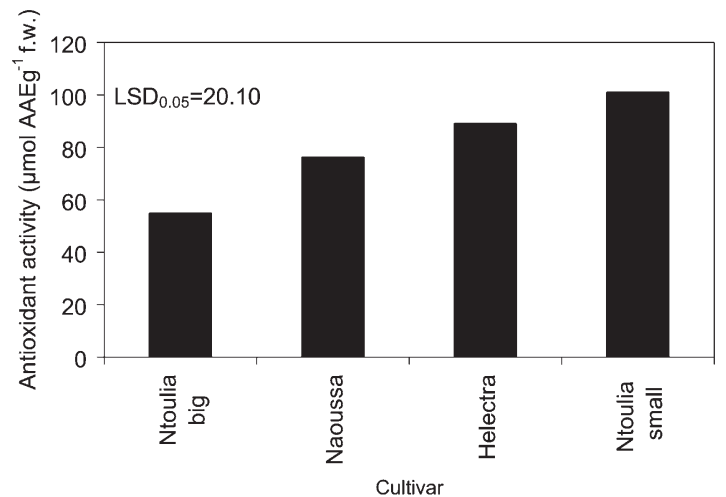

Fig. 7. Antioxidant activity of cornelian cherry cultivars. Harvest dates from left to right: 28 Aug., 1 Sept., 29 Aug., and 28 Aug.

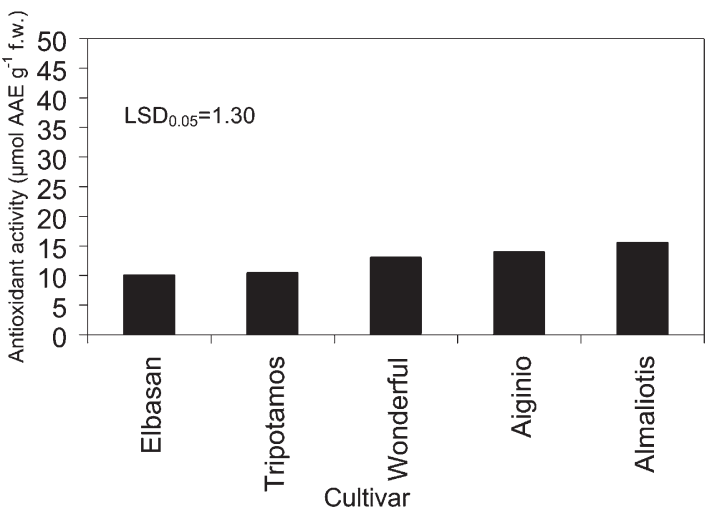

Fig. 8. Antioxidant activity of the pomegranate cultivar Wonderful and four Greek genotypes. Harvest dates from left to right: 1 Oct., 1 Oct., 2 Oct., 28 Sept., and 30 Sept. method, but there are other non-red phenolics with high AAE. Usenik et al. (2008) concluded that antioxidant activity of sweet cherries is not related only to phenolics or anthocyanins, but depends on different chemical attributes and is specific for each cultivar.
In conclusion, cornelian cherries had very high antioxidant activities followed by jujube and cherries. High antioxidant activities of some apple, pear, plum, peach, and persimmon cultivars were also recorded. This knowledge will be useful for the decision of which cultivars are better to be grown to satisfy customers' demand for fruits with high antioxidant activities.

\section{Literature Cited}

Benzie, I. and J. Strain. 1996. The ferric reducing ability of plasma (FRAP) as a measure of 
'antioxidant power': The FRAP assay. Anal. Biochem. 239:70-76.

De Gara, L., M.C. de Pinto, and F. Tommasi. 2003. The antioxidant systems vis-à-vis reactive oxygen species during plant-pathogen interaction. Plant Physiol. Biochem. 41:863-870.

Garcia-Alonso, M., S. de Pascual-Teresa, C. Santos-Buelga, and J.C. Rivas-Gonzalo. 2004. Evaluation of the antioxidant properties of fruits. Food Chem. 84:13-18.

Ghiselli, A., M. Serafini, G. Maiani, E. Azzini, and A. Ferro-Luzzi. 1995. A fluorescence-based method for measuring total plasma antioxidant capability. Free Radic. Biol. Med. 18: 29-36.

Guo, C., J. Yang, J. Wei, Y. Li, J. Xu, and Y. Jiang. 2003. Antioxidant activities of peel, pulp and seed fractions of common fruits as determined by FRAP assay. Nutr. Res. 23:1719-1726.

Hakkinen, S., M. Heinonen, S. Karenlampi, H. Mykkanen, J. Rouskanen, and R. Torronen. 1999. Screening of selected flavonoids and phenolic acids in 19 berries. Food Res. Intl. 32:345-353.

Halvorsen, B.L., K. Holte, M.C.W. Myhrstad, I. Barikmo, E. Hvattum, S.F. Remberg, A.B. Wold, K. Haffner, H. Baugerod, L.F.
Andersen, J.Ø. Moskaug, D.R. Jacobs, Jr., and R. Blomhoff. 2002. A systematic screening of total antioxidants in dietary plants. J. Nutr. 132:461-471.

Hodges, D.M., G.E. Lester, K.D. Munro, and P.M.A. Toivonen. 2004. Oxidative stress: Importance for postharvest quality. HortScience 39:924-929.

Karadeniz, F., H.S. Burdurlu, N. Koca, and Y. Soyer. 2005. Antioxidant activity of selected fruits and vegetables grown in Turkey. Turk. J. Agr. For. 29:297-303.

Larson, R.A. 1988. The antioxidants of higher plants. Phytochemistry 27:969-978.

Pellegrini, N., M. Serafini, B. Colombi, D. del Rio, S. Salvatore, M. Bianchi, and F. Brighenti. 2003. Total antioxidant capacity of plant foods, beverages and oils consumed in Italy assessed by three different in vitro assays. J. Nutr. 133:2812-2819.

Pellegrini, N., P. Simonetti, C. Gardana, O. Brenna, F. Brighenti, and P.G. Pietta. 2000. Polyphenol content and total antioxidant activity of vini novella (young red wines). J. Agr. Food Chem. 48:732-735.

Strangeland, T., F.S. Remberg, and A.K. Lye. 2009. Total antioxidant activity in 35 Ugan- dan fruits and vegetables. Food Chem. 113: $85-91$.

Tural, S. and I. Koca. 2008. Physico-chemical and antioxidant properties of cornelian cherry fruits (Cornus mas L.) grown in Turkey. Sci. Hort. 116:362-366.

Usenik, V., J. Fabcic, and F. Stampar. 2008. Sugars, organic acids, phenolic composition and antioxidant activity of sweet cherry (Prunus avium L.). Food Chem. 107:185-192.

Van der Sluis, A.A., F. Dekker, A. de Jager, and W.M.F. Jongen. 2001. Activity and concentration of polyphenolic antioxidants in apple: Effect of cultivar, harvest year, and storage conditions. J. Agr. Food Chem. 49:3606-3613.

Vangdal, E. and R. Slimestad. 2006. Methods to determine antioxidative capacity in fruit. J. Fruit Ornam. Plant Res. 14:123-131.

Wang, H. and G. Cao. 1996. Total antioxidant capacity of fruits. J. Agr. Food Chem. 44:701-705.

Wang, H., G. Cao, and R.L. Prior. 1997. Oxygen radical absorbing capacity of anthocyanins. J. Agr. Food Chem. 45:304-309.

Wojdyło, A., J. Oszmiański, and P. Laskowski. 2008. Polyphenolic compounds and antioxidant activity of new and old apple varieties. J. Agr. Food Chem. 56:6520-6530. 